\section{The spatial distribution of Aedes aegypti and Aedes albopictus in a transition zone, Rio de Janeiro, Brazil}

\author{
Padrões da distribuição espacial do Aedes aegypti \\ e Aedes albopictus em uma zona de transição \\ no Rio de Janeiro, Brasil
}

\author{
1 Instituto Oswaldo Cruz, \\ Fundação Oswaldo Cruz, \\ Rio de Janeiro, Brasil. \\ 2 Departamento de Zoologia, \\ Universidade Federal de \\ Pernambuco, Recife, Brasil. \\ ${ }^{3}$ Instituto de Comunicação \\ e Informação Científica \\ e Tecnológica em Saúde, \\ Fundação Oswaldo Cruz, \\ Rio de Janeiro, Brasil. \\ 4 Escola Nacional de Saúde \\ Pública Sergio Arouca, \\ Fundação Oswaldo Cruz, \\ Rio de Janeiro, Brasil. \\ Correspondence \\ N. A. Honório \\ Laboratório de Transmissores \\ de Hematozoários, Instituto \\ Oswaldo Cruz, Fundação \\ Oswaldo Cruz. \\ Av. Brasil 4365, Rio de \\ Janeiro, $R J$ \\ 21045-900, Brasil. \\ honorio@ioc.fiocruz.br
}

\begin{abstract}
Dengue fever has become the most important vector-borne viral disease in Brazil. Human facilitated transport of desiccation-resistant eggs has led to its two most important vectors, Aedes aegypti and Ae. albopictus, becoming widespread. In this paper, we report seasonal and spatial variation in larval abundances of Ae. aegypti and Ae. albopictus across a small-scale transition zone between an urban area and an urban wooded/forested area within Rio de Janeiro, Brazil. We installed 400 ovitraps across 10 sites with different human population densities and vegetation coverage. Eggs and larvae were collected for three weeks during the wet and dry seasons of 2002 and 2003. Ae. albopictus was predominantly found in the forested areas of the study site whereas in the urbanized area Ae. aegypti was more abundant. Both species peaked during the wet season. This distribution pattern, which may reflect adult flight range, may favor the co-occurrence of larvae of these species in a small-scale urban/urban forest transition zone.
\end{abstract}

Aedes; Dengue; Spatial Analysis
Nildimar Alves Honório 1 Márcia Gonçalves Castro 1 Fábio Saito Monteiro de Barros 2 Mônica de Avelar Figueiredo Mafra Magalhães 3 Paulo Chagastelles Sabroza 4

\section{Introduction}

The reemergence of dengue fever in Brazil began in 1986, a few years after the recolonization of the country by its main vector Aedes aegypti. The other potential dengue vector, Ae. albopictus, was discovered in Brazil in 1986. Factors such as human-facilitated transportation of desiccationresistant eggs have led to Ae. aegypti and Ae. albopictus becoming widespread. In addition, the Brazilian climate offers favorable conditions for the invasion and expansion of dengue vectors 1 . The spread of dengue vectors is helped by the intensity, frequency and speed at which people and cargo are transported within the country 2. A recent study, conducted in Nova Iguaçu in the metropolitan area of Rio, showed that densely populated neighborhoods located close to highways with intense traffic can facilitate the introduction and circulation of dengue viruses 3,4 . In these areas, strategic points such as gasoline stations, tire shops and scrap metal yards are strategically important for the surveillance of dengue vectors 3

Ae. aegypti and Ae. albopictus are sympatric species that tend to breed in similar sites, most commonly in artificial containers 5,6. Inter-specific competition between these species has been documented. Early work suggested $A e$. aegypti to be the superior competitor 7. More recent works, however, have shown that Ae. albopictus may be superior under laboratory 8,9 and 
field conditions 10,11, which probably explains displacements of Ae. aegypti by Ae. albopictus in some areas 10,12. In North America and Brazil, the introduction of Ae. albopictus has been associated with a decrease in the abundance of $A e$. aegypti 13,14 , with an impact on the geographical distribution of this species 15,16,17.

Urbanization and vegetation coverage seem to have significant but opposite effects on the occurrences of Ae. aegypti and Ae. albopictus 18. Studies conducted in the Tijuca Forest in Rio de Janeiro 19,20, showed that Ae. aegypti and Ae. albopictus were more abundant near houses than deeper in the forest 19. The dispersal of Ae. aegypti and Ae. albopictus, estimated using mark-releaserecapture techniques, showed that Ae. albopictus can fly between sylvatic and peridomestic environments while Ae. aegypti had a lower tendency to disperse into the forest 20 , suggesting that the urban forest is a refuge for Ae. albopictus.

Several authors have shown that Ae.aegypti is more prevalent in highly urbanized and densely populated neighborhoods, whereas Ae. albopictus is more prevalent in rural, suburban, and forested urban areas 17,18,19,20,21,22. However, most of these studies have analyzed the distribution of Ae. aegypti and Ae. albopictus on a large (city) scale. The goal of the present study was therefore to add further analysis to this process by looking at Ae. aegypti and Ae. albopictus distribution patterns at a local scale. In this paper, we report seasonal fluctuations in the larval occurrences of Ae. aegypti and Ae. albopictus across a spatially heterogeneous landscape, characterized by two distinct habitats - a highly populated low income urban area, and a vegetated, more sparsely populated area - separated by a sharp transition zone (the border of the Oswaldo Cruz Foundation - FIOCRUZ - campus), in the city of Rio de Janeiro. By characterizing the seasonal and spatial variation in the larval density of both species, we attempted to address the factors contributing to the competitive advantages for each species.

\section{Material and methods}

\section{Study site}

The area encompasses the campus of FIOCRUZ,

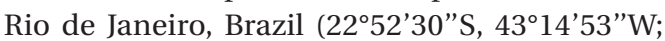
$697,000 \mathrm{~m}^{2}$ ), with large vegetation patches, and the surrounding area, which are densely populated by low income residents and known as slums (comunidades or favelas) (Figure 1). This forested area within the campus is a refuge for a variety of mammals and birds. Ten collecting sites were defined, each representing different levels of an- thropic modifications, types of urbanization and land use. Table 1 lists the main characteristics of these sites.

The climate in Rio is tropical, with a drier winter (May-September) and a rainy summer (November-March). Air temperature and precipitation data were obtained from the nearest meteorological station, located $10 \mathrm{~km}$ from the study site.

\section{Classification of land coverage \\ and infestation maps}

A visual review of an aerial photograph of the area allowed us to classify the study area into four zones: (1) densely built urban - an area composed mainly of residential and commercial buildings; (2) low vegetation coverage - an area composed of short vegetation, mostly grass; (3) medium vegetation coverage - an area composed of average size vegetation, shrubs or small trees that were spatially scattered; and (4) high vegetation coverage - an area composed mainly of tall vegetation, in patches (Figure 1). Maps showing the spatial distribution of Ae. aegypti and Ae. albopictus larval density in wet and dry seasons were created using a kernel density estimator (Gaussian function and smooth kernel of $100 \mathrm{~m}$ radius. ArcGis 9.1, ESRI; http://www.esri.com/software/ arcgis/index.html). The kernel density estimator that was chosen is an interpolation and smoothing technique for generalizing point location to an entire area and consists of a bi-dimensional function of the events, forming a surface whose value is proportional to the intensity of samples for the area 23 .

\section{Entomological survey}

Four entomological surveys were carried out during the wet and dry seasons of 2002 and 2003. In each of the ten study sites (Figure 1), we installed 40 ovitraps (a plastic vase with a wooden oviposition paddle and hay infusion as described previously) ${ }^{16}$. After seven days, eggs and larvae were collected. This procedure was repeated during three consecutive weeks. Larvae were identified and counted in the laboratory. Paddles were stored at $25-28^{\circ} \mathrm{C}$ and $>80 \%$ humidity and immersed in water after two weeks; hatching larvae were reared up until the fourth instar, and identified using key by Consoli \& Lourenço-de-Oliveira 24.

\section{$\underline{\text { Statistical analysis }}$}

Analysis of variance (ANOVA) was used for testing seasonal and spatial trends of the log-trans- 
The study site was an urban/urban forest in a small-scale transition zone.

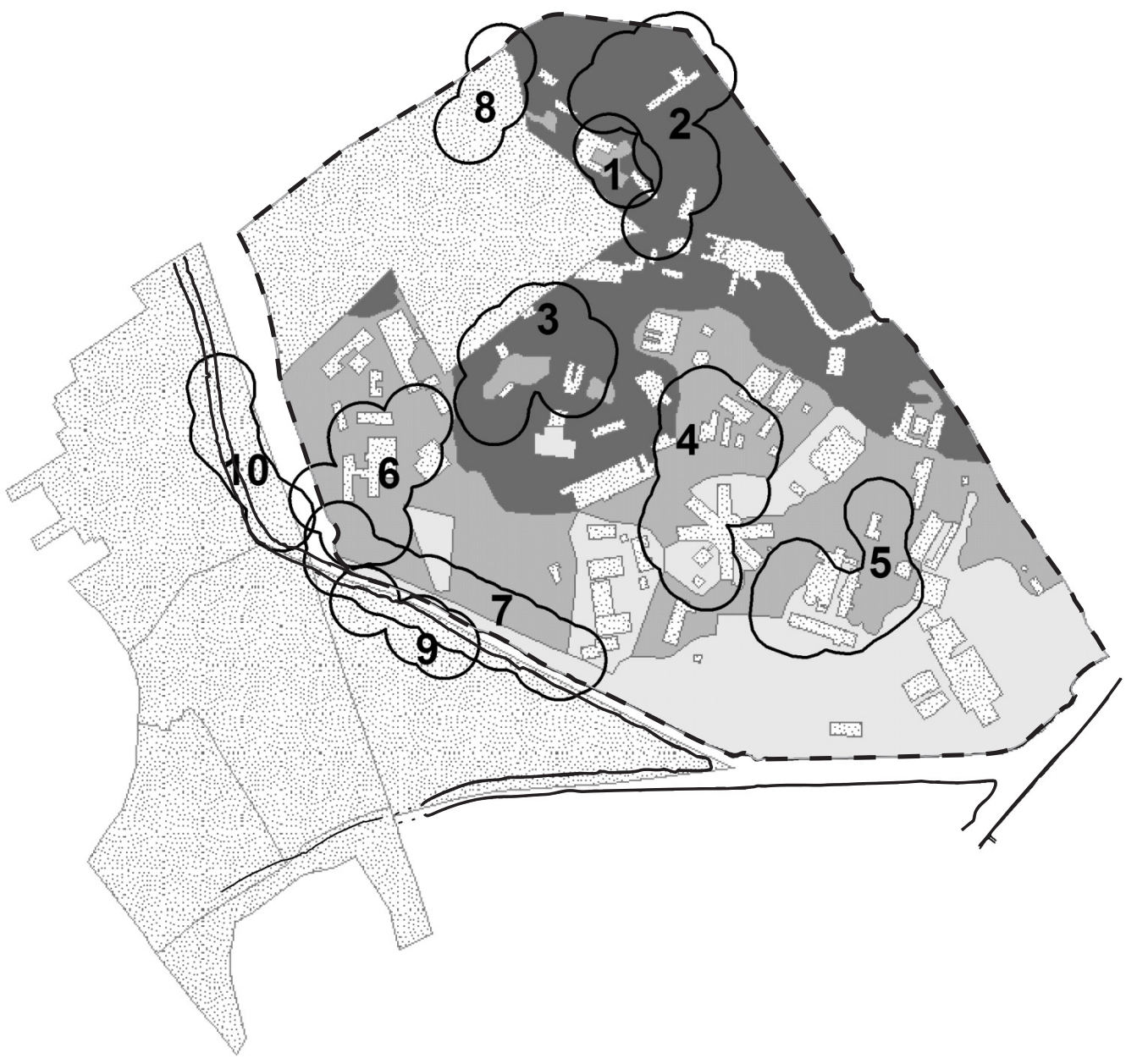

Areas

1 - Arthur Neiva Pavillon

2 - Carlos Chagas Pavillon

3 - Garden

4 - Day Care Center/INCQS

5 - IPEC

6 - ENSP/FarManguinhos

7 - Faria Timbó River

8 - Amorim Community

9 - Varginha Community

10 - Parque João Goulart Community

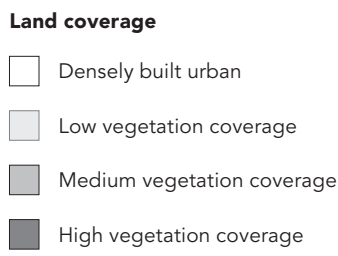

Densely built urban

Low vegetation coverage

Medium vegetation coverage

High vegetation coverage

$\left.w\right|_{S} ^{N} E$
0

560 
Main characteristics of the descriptors of each site within and outside of FIOCRUZ campus, Rio de Janeiro, Brazil.

\begin{tabular}{|c|c|c|c|c|c|c|c|}
\hline \multirow[t]{2}{*}{ Sites } & \multirow{2}{*}{$\begin{array}{l}\text { Distance } \\
\text { from the } \\
\text { border }(m)\end{array}$} & \multirow{2}{*}{$\begin{array}{l}\text { Area } \\
\left(\mathrm{m}^{2}\right)\end{array}$} & \multirow{2}{*}{$\begin{array}{c}\text { Exposed } \\
\text { human } \\
\text { population * } \\
\text { (approximate) }\end{array}$} & \multicolumn{4}{|c|}{ Land coverage } \\
\hline & & & & $\begin{array}{c}\% \\
\text { urban }\end{array}$ & $\begin{array}{c}\% \text { low } \\
\text { vegetation }\end{array}$ & $\begin{array}{l}\% \text { medium } \\
\text { vegetation }\end{array}$ & $\begin{array}{c}\% \text { high } \\
\text { vegetation }\end{array}$ \\
\hline $\mathrm{C} 1$ * & 52 & $12,071.63$ & 65 * & 21.06 & 0.00 & 15.81 & 63.13 \\
\hline $\mathrm{C} 2$ * & 109 & $49,895.80$ & 119 * & 7.27 & 0.00 & 0.00 & 85.21 \\
\hline $\mathrm{C} 3$ * & 66 & $38,381.01$ & 30 * & 16.67 & 0.00 & 11.94 & 71.04 \\
\hline $\mathrm{C} 4$ * & 340 & $48,975.61$ & 460 * & 20.69 & 21.97 & 54.32 & 3.01 \\
\hline $\mathrm{C} 5$ * & 254 & $39,688.21$ & 285 * & 17.60 & 26.96 & 55.45 & 0.00 \\
\hline $\mathrm{C} 6$ * & 88 & $38,631.98$ & 756 * & 19.58 & 0.85 & 68.81 & 0.00 \\
\hline $\mathrm{C} 7$ * & 10 & $50,756.49$ & 10 * & 27.01 & 22.64 & 34.34 & 0.00 \\
\hline P8 ** & -82 & $18,545.67$ & 3,199 * & 73.33 & 0.00 & 0.00 & 12.30 \\
\hline $\mathrm{PQ}$ ** & -50 & $19,348.76$ & 1,175 * & 82.34 & 6.49 & 0.04 & 0.00 \\
\hline $\mathrm{P} 10$ ** & -43 & $25,364.43$ & 4,923 * & 89.77 & 0.00 & 0.00 & 0.00 \\
\hline
\end{tabular}

* Exposed population inside forested area (FIOCRUZ Campus) was obtained from the

Human Resources Department of FIOCRUZ;

** Data of respected population in slums were obtained from the Instituto Brasileiro de Geografia e Estatística (IBGE).

formed occurrences of immature specimens. Simple Pearson correlations were used to test for associations between species densities. Least squares regression was used for fitting exponential models for infestation vs. distance. The slope of the regression line for each season were compared as described by Zar 25 .

\section{Results}

\section{Specimens}

A total of 57,779 immature mosquito specimens were collected, $41 \%$ of which were Ae. aegypti and $59 \%$ Ae. albopictus.

\section{Spatial distribution}

No significant difference was observed between the log transformed mean number of larvae obtained at the first, second, and third weeks of each collecting period. Ae. albopictus was more abundant in areas with high to medium dense vegetation coverage $\left(\mathrm{F}_{1,118}=78.63, \mathrm{p}<0.001\right)$, whereas densely populated areas were dominated by Ae. aegypti $\left(\mathrm{F}_{1,118}=94.82, \mathrm{p}<0.001\right)$. The species co-occurred at the transition zone between highly populated and highly vegetated areas (Figures 2 and 3). Figure 4 shows the result of fitting a linear regression line to log (larvae) $\mathrm{x}$ distance from the campus border $\left(\mathrm{r}^{2}=0.78\right.$,
$\mathrm{F}_{1,6}=21.74[\mathrm{p}<0.01]$ for the wet season and $\mathrm{r}^{2}=$ $0.84, \mathrm{~F}_{1,6}=32.39$ [p $<0.01$ ] for the dry season). In the wet season, the regression curve was: [proportion Ae. aegypti] $=1.5115(\exp ([$ distance $][-$ $0.0065]$ ). From this model, we estimate that $72 \%$ of Ae. aegypti larvae were within 50m from the border, approximately $50 \%$ at $100 \mathrm{~m}$, and only $3.8 \%$ beyond $500 \mathrm{~m}$. For the dry season, the regression curve was: [proportion Ae. aegypti] $=1.6793(\exp ([$ distance $][-0.0056])$, suggesting slightly wider larval distribution. For example, $57 \%$ would fly $100 \mathrm{~m}$ and $6 \%$ would fly $500 \mathrm{~m}$. The slope of the regression line for each season did not differ significantly (Student's t-test).

\section{Seasonal variations}

Approximately $50 \%$ and $28 \%$ of all Ae. albopictus and Ae. aegypti larvae were collected during the wet season and summer, respectively. The percentage of positive ovitraps also varied between seasons. After a period with positive traps typically $<50 \%$ during the wet season of 2003 , we observed an increase in both Ae. aegypti and Ae. albopictus frequencies (mean percent of positive ovitrap of $\sim 90 \%$ ). Seasonal variation in rainfall and temperature is shown in Figure 5. Outside the forest area, both species showed similar temporal patterns, characterized by relatively constant densities during the first year, but with a peak in the wet season of 2003, and a return to the baseline level (Figure 6). Rainfall indices varied 
Figure 2

Mean density per site of immatures of Aedes aegypti (white cycle) and Aedes albopictus (black cycle) as a function of distance from the border of the forest area, human population, and \% vegetation coverage.

2a) Distance from the campus border

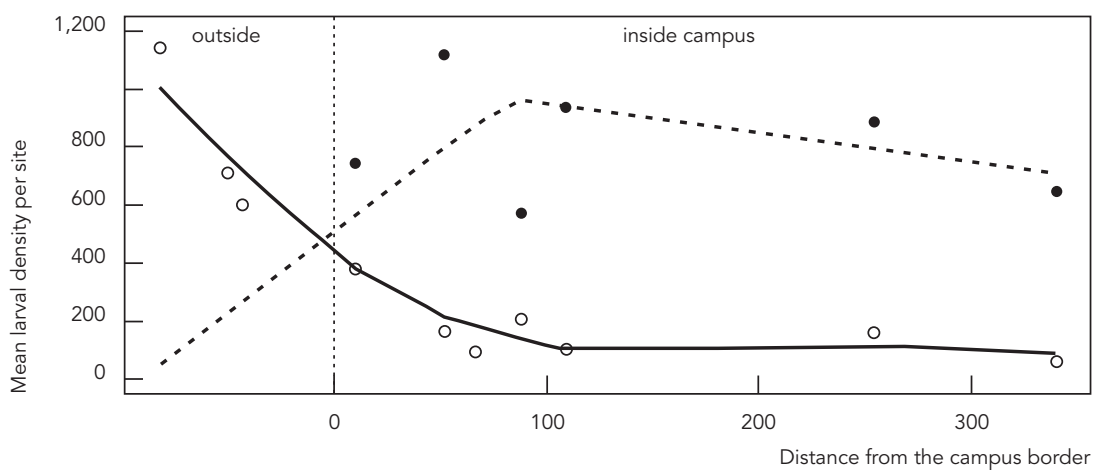

2b) Human population

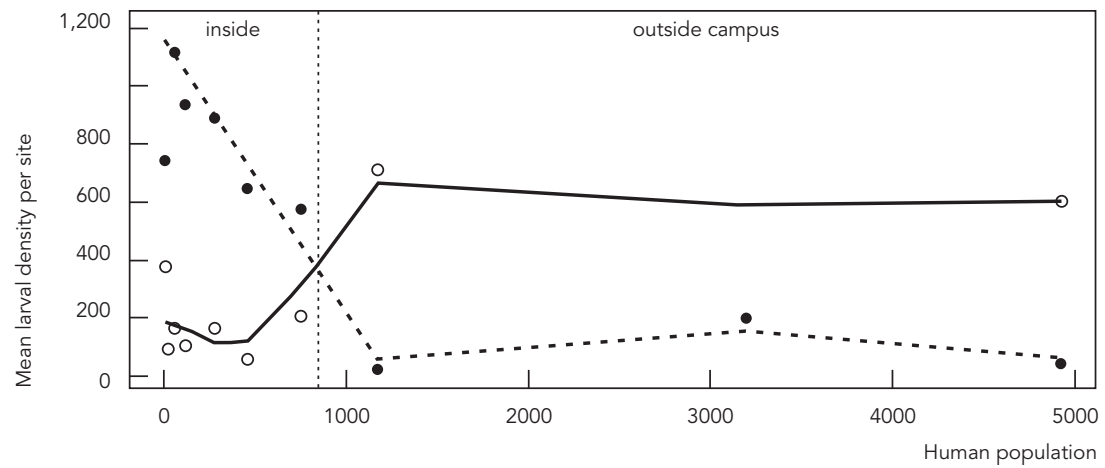

2c) \% vegetation coverage

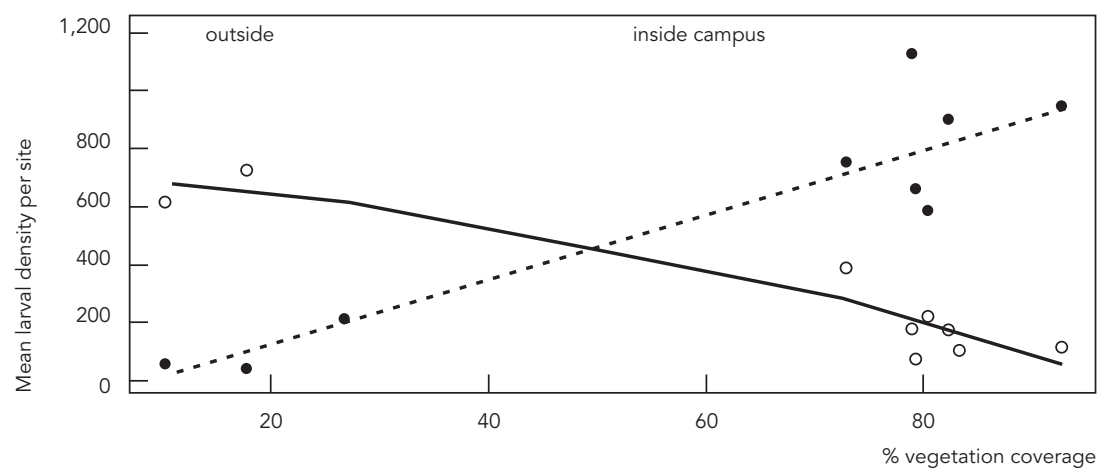


Figure 3

Kernel estimation of density of immatures of Aedes aegypti and Aedes albopictus inside and outside of forest area during wet and dry seasons, 2002 and 2003. Sizes of the circles indicate abundance of larval density.

3a) e. e y $t$ - wet 2002

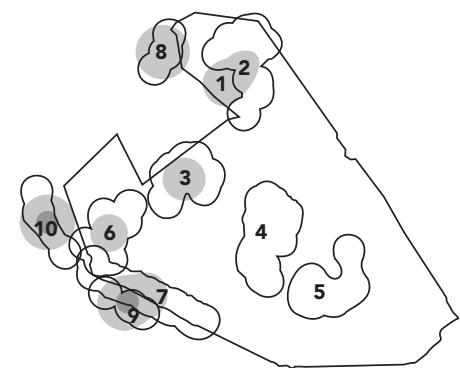

3c) e. e y $t$-dry 2002

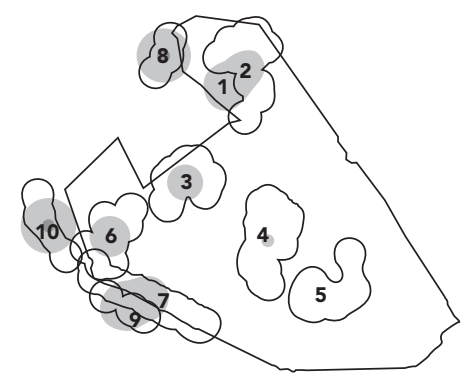

3e) e. e y $t$-wet 2003

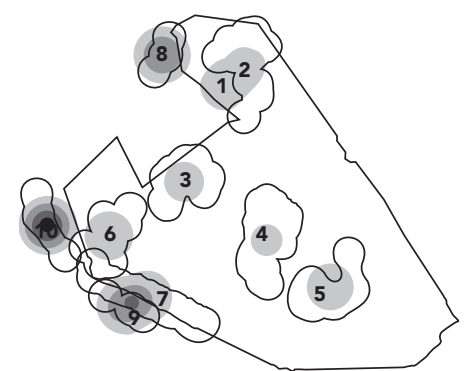

3g) e. e y $t$-dry 2003

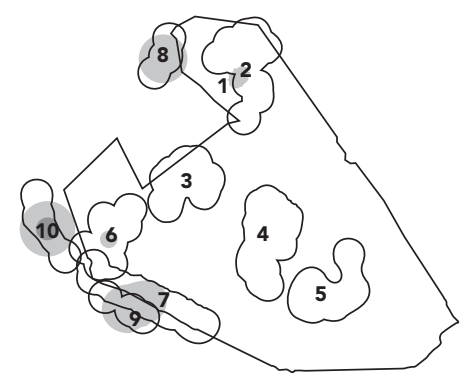

3b) e. 1 o ct s-wet 2002

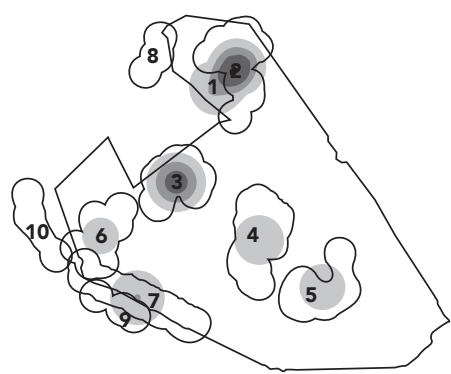

3d) e. 1 o ct s-dry 2002

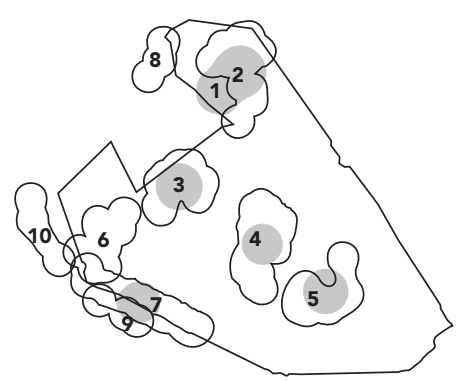

3f) e. 1 o ct s-wet 2003

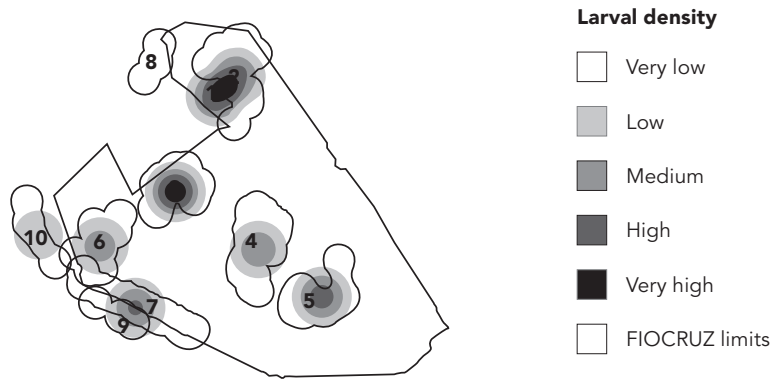

3h) e. 1 o ct s-dry 2003

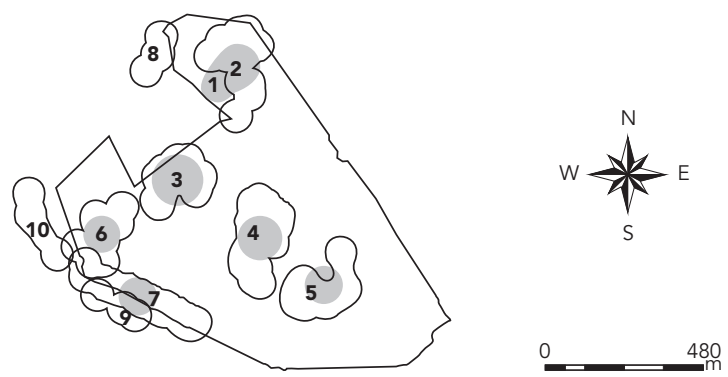


Ae. aegypti AND Ae. albopictus SPATIAL DISTRIBUTION PATTERN

1209

Figure 4

Percentage of Aedes aegypti larvae retrieved, as compared to the number obtained in the urbanized area, decreased exponentially with the distance to the wall of the forest area. The lines represent the least squares regression fit of the data for the function $y=b^{*} \exp \left(x^{*} a\right)$, during the wet season (circles) and dry season (squares).
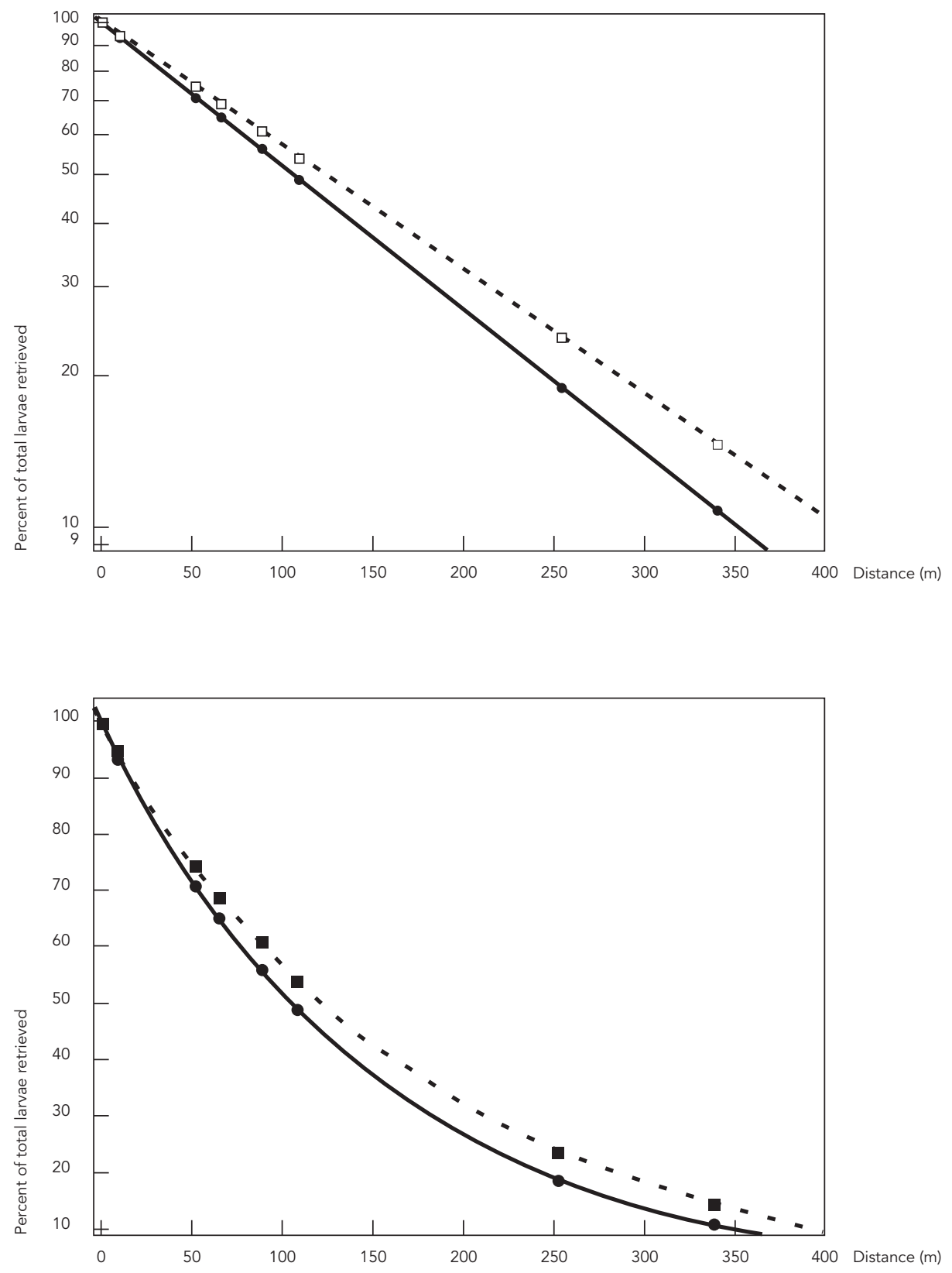

Cad. Saúde Pública, Rio de Janeiro, 25(6):1203-1214, jun, 2009 
Total rainfall and mean temperature per month, 2002 and 2003. Vertical bars indicate maximum and minimum mean monthly temperature. Arrows indicate periods of data collection.

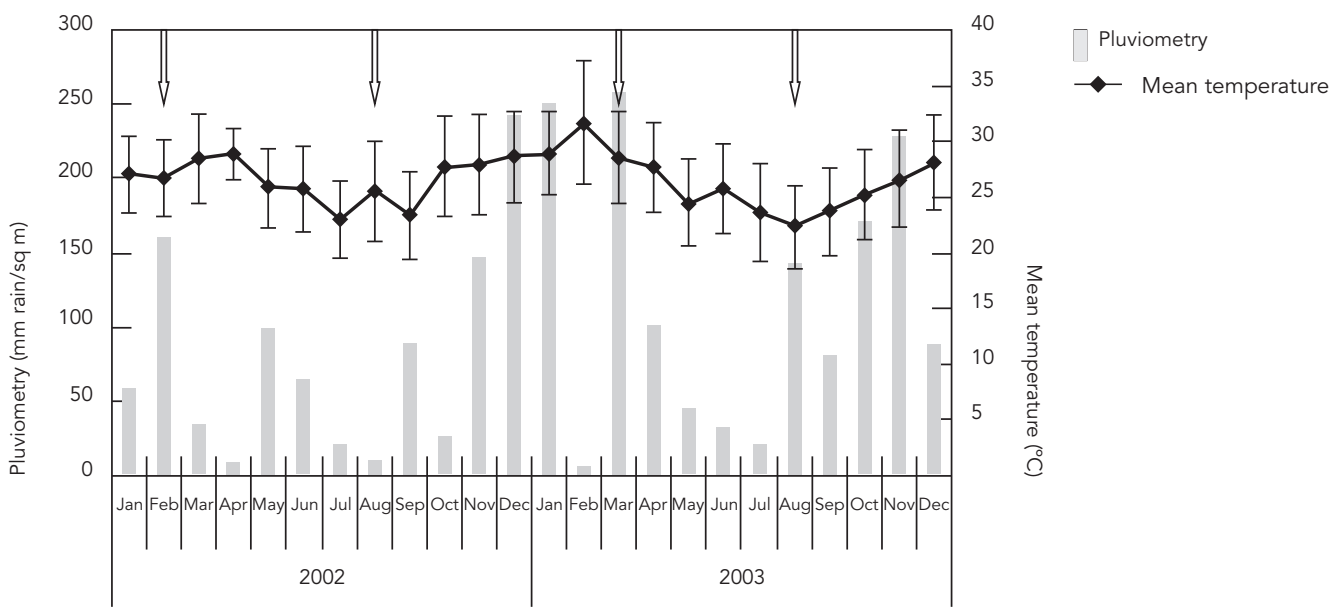

intra-seasonally depending on the year, particularly for some months of the year. The years 2002 and 2003 showed distinct rainfall regimes: rainfall peaked in February in 2002, and one month later, in 2003; the spring rainfall started later in 2002 (September) than in 2003 (August); and in December, it rained twice as much in 2002 as in 2003. The thermal variation range was bigger in 2003 than 2002 (Figure 5).

In the forested area, Ae. aegypti followed the same pattern observed outside the forested area, but always at a lower density than inside (Table 2). Overall, the density of Ae. albopictus was twice that of Ae. aegypti inside the forested area (Table 3 ; Figure 6).

\section{Discussion}

Our results show Ae. albopictus was more abundant in areas with high to medium dense vegetation coverage, whereas the densely populated areas were dominated by Ae. aegypti. These results are consistent with distribution patterns of Ae. aegypti (in urban areas) and Ae. albopictus (in more densely vegetated areas) found in the literature 17,18,19,20,21,22. Ae. albopictus was found associated with vegetated areas mostly inside the forested area of FIOCRUZ Campus (Figures 1 and 3 ), where vegetation coverage is highest. Coexistance occurred at the transition zone, defined as the area that covers the campus wall and its vicinity (Figure 3). Similarly, co-occurrence of the two species has been reported in suburban areas in Rio de Janeiro 17,22. We hypothesize that the host-seeking behavior of Ae. albopictus may play a role in this distribution. Areas 4 and 5, with lowmedium vegetation coverage, in the center of the forest area were systematically less positive to $A e$. albopictus than other areas. This may be due to low vegetation coverage.

Both species showed seasonal variation in their larval densities. Overall larval densities for both Ae. aegypti and Ae. albopictus were greater during the wet seasons (Figure 6). Variation was more marked in Ae. albopictus (Figures 2, 3, and $6)$. This is in concordance with previous studies in Rio de Janeiro 6. In the dry season of 2002, Ae. albopictus and Ae. aegypti mean densities decreased in the forest area, but remained constant in the densely built urban area. Ae. aegypti was more abundant in the wet season of 2003 than it was in the wet season of 2002. The same was true for Ae. albopictus. These may have been due to higher rainfall indices in March (Figure 5).

Data suggest that Ae. aegypti has a more stable response to climatic variation. The main cause of the shift in distribution of the two species may be due to a greater increase in egg mortality for Ae. albopictus under dry conditions, compared to Ae. aegypti 26 . Therefore, dry conditions could shift the competitive advantage away from $A e$. 
Mean number of Aedes aegypti larvae retrieved at each ovitrap area in the wet and dry seasons, 2002 and 2003.

\begin{tabular}{lcccccccc}
\hline Sites * & & \multicolumn{2}{c}{2002} & & & 2003 & \\
& Wet & SD & Dry & SD & Wet & SD & Dry & SD \\
& & & & & & & & \\
C1 & 119.00 & 79.67 & 144.67 & 190.00 & 165.00 & 41.62 & 25.00 & 10.58 \\
C2 & 57.00 & 46.51 & 77.00 & 35.93 & 103.00 & 55.03 & 35.67 & 48.43 \\
C3 & 109.00 & 70.55 & 71.67 & 46.82 & 92.00 & 19.97 & 1.00 & 1.73 \\
C4 & 28.00 & 24.27 & 37.33 & 28.75 & 60.67 & 30.73 & 12.00 & 11.14 \\
C5 & 25.00 & 12.00 & 33.33 & 22.23 & 161.67 & 163.84 & 24.33 & 28.04 \\
C6 & 75.33 & 58.48 & 98.67 & 79.86 & 207.00 & 49.49 & 40.00 & 38.22 \\
C7 & 123.00 & 34.60 & 135.00 & 43.49 & 377.67 & 237.00 & 108.33 & 168.66 \\
P8 & 435.67 & 184.91 & 370.33 & 99.45 & 1142.67 & 519.56 & 470.67 & 228.82 \\
P9 & 362.67 & 243.66 & 376.33 & 240.67 & 711.33 & 319.31 & 174.33 & 95.10 \\
P10 & 391.33 & 177.18 & 183.00 & 72.92 & 602.33 & 295.63 & 141.67 & 87.46 \\
\hline
\end{tabular}

Note: standard deviations (SD) for the three weeks are reported.

* Site codes correspond to those in Figure 1.

Table 3

Mean number of Aedes albopictus larvae retrieved at each collecting area in the wet and dry seasons, 2002 and 2003.

\begin{tabular}{lcccccccc}
\hline Sites * & \multicolumn{2}{c}{2002} & & & & 2003 & \\
& Wet & SD & Dry & SD & Wet & SD & Dry & SD \\
\hline C1 & 418.00 & 266.27 & 165.67 & 104.85 & $1,114.33$ & 402.01 & 66.00 & 64.44 \\
C2 & $1,007.67$ & 689.39 & 298.33 & 96.73 & 934.67 & 295.05 & 116.33 & 31.34 \\
C3 & 888.67 & 95.71 & 138.67 & 202.23 & $1,276.67$ & 367.22 & 253.00 & 112.28 \\
C4 & 192.67 & 23.01 & 97.33 & 124.42 & 647.33 & 266.04 & 119.00 & 41.00 \\
C5 & 140.33 & 59.54 & 127.33 & 132.67 & 886.67 & 423.02 & 80.00 & 32.79 \\
C6 & 72.33 & 53.16 & 15.33 & 10.12 & 572.67 & 132.88 & 75.33 & 51.83 \\
C7 & 357.00 & 94.91 & 94.00 & 33.41 & 741.67 & 234.51 & 71.33 & 44.00 \\
P8 & 31.33 & 3.06 & 10.33 & 10.12 & 200.33 & 177.80 & 30.00 & 22.61 \\
P9 & 5.00 & 6.24 & 5.67 & 9.81 & 27.33 & 18.58 & 10.33 & 8.96 \\
P10 & 1.00 & 1.00 & 15.33 & 26.56 & 44.00 & 3.46 & 7.67 & 10.79 \\
\hline
\end{tabular}

Note: standard deviations (SD) for the three weeks are reported.

* Site codes correspond to those in Figure 1.

albopictus, favoring Ae. aegypti, a pattern documented in controlled laboratory environments 27. Nevertheless, the greater stability in Ae. aegypti numbers in urban areas could also be due to its habitat preference for domestic situations 22 . The relatively protected environment provided by housing may favor stable year-long breeding site availability 20,22.

Our results suggest that the occurrence of both species varies seasonally and spatially (Figures 2, 3 and 6). Ae. aegypti and Ae. albopictus were more common in the area closer to the border inside FIOCRUZ Campus and Ae. albopictus was practically absent inside the densely built urban area. Although there was no statistically significant negative correlation for any of the periods separately, the overall densities of both species in the small transition zones were negatively correlated, despite parallel seasonal fluctuations. Because these species colonize distinct habitats in Rio de Janeiro, Ae. albopictus may not replace Ae. aegypti, and both species may be common in a single area with their abundances positively correlated 17 . Also, as suggested in studies in Florida, USA, local coexistence of these species may be possible in a seasonal climate because warm, 
Mean number of Aedes aegypti and Aedes albopictus larvae retrieved in ovitraps in the outskirts of and inside the forest area (campus).

6a) Outskirts

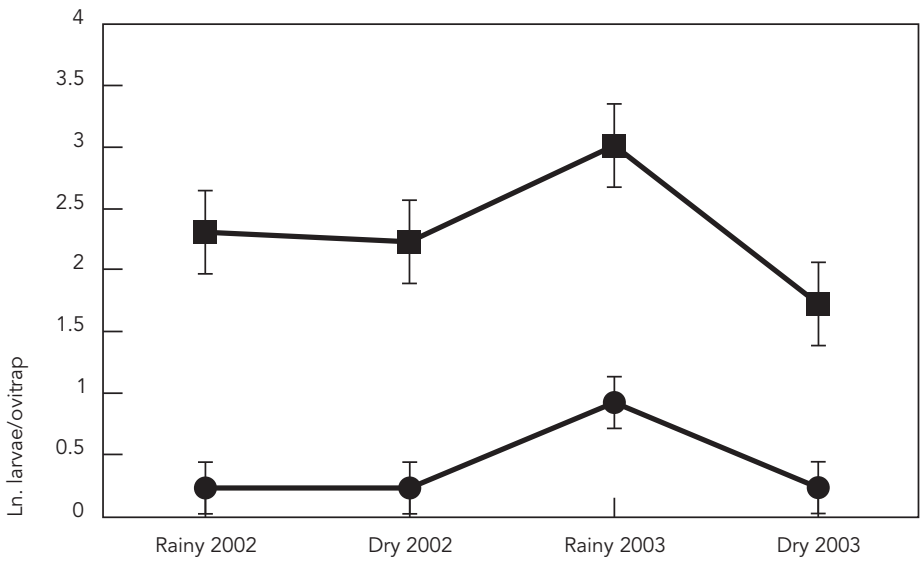

- Ln Ae. albopictus larvae/ovitrap

- Ln Ae. aegypti larvae/ovitrap

6b) Campus

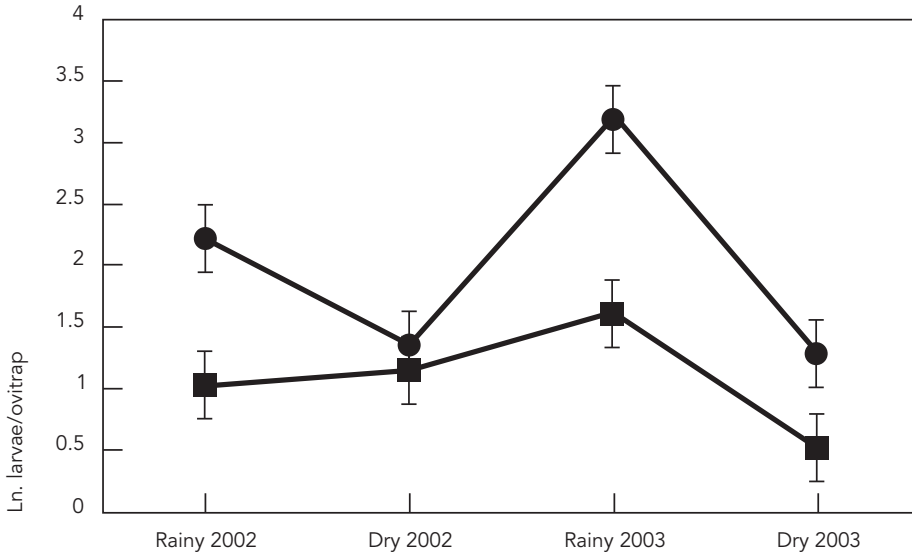

Note: vertical bars denote $95 \%$ confidence intervals.

dry climates favor Ae. aegypti and reduce the impact of competition from Ae. albopictus through differential mortality of Ae. albopictus eggs 26.

The usual > 1 ratio of Ae. albopictus to Ae. aegypti larvae was inverted during the dry season of 2002, when Ae. albopictus eggs and larvae suffered a decrease in specimen numbers. However, Ae. aegypti densities did not increase in collecting sites where Ae. albopictus densities remained constant, and this could be a factor related to the distance to the urban area. During the 2003 wet season, when the percentage of positive ovitraps was high, there was a $50 \%$ mean decrease in the expected densities of Ae. aegypti, as estimated by the flight range equation. This expected density decrease was most marked in densely vegetated areas, where Ae. albopictus was most prevalent.

Due to the low proportion of larvae of $A e$. aegypti that occurred in natural habitats compared to artificial containers 28 , we were able to estimate the number of Ae. aegypti larvae in the FIOCRUZ campus as a function of the distance 
to the urbanized area. The exponential model for Ae. aegypti larvae distribution indicates that occurrence of immature forms would be common in the neighboring areas, near the preferred habitat, but would decrease markedly as the distance increased. This distribution pattern, as well as the increased densities of Ae. albopictus larvae in the vegetated area, would favor the co-occurrence of larvae of both species.

We have reported seasonal and spatial variations in distribution patterns between Ae. aegypti and $A e$. albopictus within a habitat transition zone. These results suggest that Ae.aegypti and Ae. albopictus are differentially distributed over hab- itats and that their numbers may decrease exponentially in relation to the distance traveled 16,18 . This means that a high rate of both species would be present in a small scale transition zones and inter-specific competition could play a role in these urban/urban-forested transition zones, especially when the number of available breeding sites becomes scarce. Longitudinal studies with more frequent sampling may uncover regular seasonal waves of species invasion and retreat in these areas. Further characterization of transition zones may provide a better insight into the interplay of population dynamics of dengue vectors in small-scale habitats.

\section{Resumo}

Dengue tornou-se a mais importante doença viral transmitida por vetores no Brasil. O transporte humano de ovos resistentes à dessecação permitiu que seus dois mais importantes vetores, Aedes aegypti $e$ Ae. albopictus, se tornassem cosmopolitas. Neste artigo, nós avaliamos a variação sazonal e espacial da abundância de larvas de Ae. aegypti $e$ Ae. albopictus por meio de uma pequena escala espacial de zona de transição entre uma área urbana e uma área florestal do Rio de Janeiro, Brasil. Foram instaladas quarenta ovitrampas em cada área dos dez locais caracterizados por diferente densidade populacional humana e cobertura vegetal. Ovos e larvas foram coletados durante três semanas no verão e inverno de 2002 e 2003. Ae. albopictus foi predominantemente encontrado nas áreas com maior cobertura vegetal enquanto que nas áreas urbanizadas (comunidades), Ae. aegypti foi mais abundante. Ambas as espécies apresentaram pico durante a estação chuvosa. Esse padrão de distribuição das formas imaturas pode refletir no raio de vôo do adulto, favorecer a co-ocorrência de larvas dessas espécies nessa pequena escala espacial da zona de transição entre as áreas urbana e de floresta.

Aedes; Dengue; Análise Espacial

\section{Contributors}

N. A. Honório participated in the design, planning, data collection, analysis, interpretation, and drafting of the paper. M. G. Castro participated in the design, data collection and data interpretation. F. S. M. Barros collaborated in analysis, data interpretation and drafting of the paper. M. A. F. M. Magalhães helped in the analysis and data interpretation. P. C. Sabroza contributed to the design, analysis, interpretation data, critical review of the content, and approval of the paper's final version.

\section{Acknowledgments}

Special thanks go to Ary Carvalho de Miranda and Leandro Borges de Miranda for providing logistical support that made this study possible. We thank Marcelo Quintela, Kleber Soares, Olivio F. Souza, Sandro Peixoto and Cristiano Generoso for logistical support in the field, and Manuel Luiz Campos de Souza for providing data on the human population at Oswaldo Cruz Foundation (FIOCRUZ) campus. We thank R. Lourenço-de-Oliveira, M. G. Rosa-Freitas, C. T. Codeço and S. A. Juliano for helpful comments on an earlier version of this manuscript. This work was supported by FIOCRUZ and the Diretoria de Administração do Campus at FIOCRUZ (DIRAC). 


\section{References}

1. Kuno G. Review of the factors modulation dengue transmission. Epidemiol Rev 1995; 17:321-35.

2. Tauil P. A urbanização e ecologia do dengue. Cad Saúde Pública 2001; 17 Suppl:99-102.

3. Lagrotta MF, Silva WC, Souza-Santos R. Identification of key areas for Aedes aegypti control through geoprocessing in Nova Iguaçu, Rio de Janeiro State, Brazil. Cad Saúde Pública 2008; 24:70-80.

4. Lourenço-de-Oliveira R, Honório NA, Castro MG, Schatzmayr HG, Miagostovich MP, Alves JCR, et al. Dengue virus type 3 isolation from Aedes aegypti in the municipality of Nova Iguaçu, State of Rio de Janeiro. Mem Inst Oswaldo Cruz 2002; 97:799-800.

5. Klowden MJ. Mating and nutritional state affect the reproduction of Aedes albopictus mosquitoes. J Am Mosq Control Assoc 1993; 2:169-73.

6. Honório NA, Cabello P, Codeço CT, Lourenço-deOliveira R. Preliminary data on the performance of Aedes aegypti and Aedes albopictus immatures developing in water-filled tires in Rio de Janeiro. Mem Inst Oswaldo Cruz 2006; 101:225-8.

7. Black WC, Rai KS, Turco BJ, Arroyo DC. Laboratory study of competition between United States strains of Aedes albopictus and Aedes aegypti (Diptera: Culicidae). J Med Entomol 1989; 26:260-71.

8. Barrera R. Competition and resistance to starvation in larvae of container-inhabiting Aedes mosquitoes. Ecol Entomol 1996; 21:117-27.

9. Daugherty MP, Alto BW, Juliano SA. Invertebrate carcasses as a resource for competition Aedes albopictus and Aedes aegypti (Diptera: Culicidae). J Med Entomol 2000; 37:364-72.

10. Juliano SA. Species introduction and replacement among mosquitoes: interspecific resource competition or apparent competition? Ecology 1998; 79:255-68.

11. Braks MAH, Honório NA, Lounibos LP, Lourençode-Oliveira R, Juliano SA. Interspecific competition between two invasive species of container mosquitoes, Aedes aegypti and Aedes albopictus (Diptera: Culicidae), in Brazil. Ann Entomol Soc Am 2004; 97:130-9.

12. Juliano SA, Lounibos LP, O'Meara GF. A field test for competitive effects of Aedes albopictus on A. aegypti in South Florida: differences between sites of coexistence and exclusion? Oecologia 2004; 139:583-93.

13. O'Meara GF, Evans LF, Gettman AD, Cuda JP. Spread of Aedes albopictus and decline of Aedes aegypti (Diptera: Culicidae) in Florida. J Med Entomol 1995; 32:554-62.

14. Galardo A. A dispersão do Aedes (Stegomyia) aegypti (Linnaeus 1762) e Aedes (Stegomyia) albopictus no Estado do Rio de Janeiro de 1986-2000, e sua relação com a transmissão de dengue [Dissertação de Mestrado]. Rio de Janeiro: Universidade Federal Rural do Rio de Janeiro; 2002.

15. Hawley WA. The biology of Aedes albopictus. J Am Mosq Control Assoc 1988; 4 Suppl:1-40.
16. Honório NA, Silva WC, Leite PJ, Gonçalves JM, Lounibos LP, Lourenço-de-Oliveira R. Dispersal of Aedes aegypti and Aedes albopictus (Diptera: $\mathrm{Cu}-$ licidae) in an urban endemic dengue area in the state of Rio de Janeiro, Brazil. Mem Inst Oswaldo Cruz 2003; 98:191-8.

17. Braks MAH, Honório NA, Lourenço-de-Oliveira R, Juliano SA, Lounibos LP. Convergent habitat segregation of Aedes aegypti and Aedes albopictus (Diptera: Culicidae) in southeastern Brazil and Florida. J Med Entomol 2003; 40:785-94.

18. Carbajo AE, Curto SI, Schweigmann NJ. Spatial distribution pattern of oviposition in the mosquito Aedes aegypti in relation to urbanization in Buenos Aires: southern fringe bionomics of an introduced vector. Med Vet Entomol 2006; 20:209-18.

19. Lourenço-de-Oliveira R, Castro MG, Braks MAH, Lounibos LP. The invasion of urban Forest by dengue vectors in Rio de Janeiro. J Vector Ecol 2004; 29:94-100.

20. Maciel-de-Freitas R, Neto RB, Gonçalves JM, Codeço CT, Lourenço-de-Oliveira R. Movement of dengue vectors between the human modified environment and an urban forest in Rio de Janeiro. J Med Entomol 2006; 43:1112-20.

21. Rey JR, Nishimura N, Wagner B, Braks MAH, O'Connell SM, Lounibos LP. Habitat segregation of mosquito arbovirus vectors in South Florida. J Med Entomol 2006; 43:1134-41.

22. Lima-Camara T, Honório NA, Lourenço-de-Oliveira R. Freqüência e distribuição espacial de Aedes aegypti $\mathrm{e}$ Aedes albopictus (Diptera, Culicidae) em distintos ambientes no Rio de Janeiro, Brasil. Cad Saúde Pública 2006; 22:2079-84.

23. Souza-Santos R, Carvalho MS. Análise da distribuição espacial de larvas de Aedes aegypti na Ilha do Governador, Rio de Janeiro, Brasil. Cad Saúde Pública $2000 ; 16: 31-42$.

24. Consoli RAGB, Lourenço-de-Oliveira R. Principais mosquitos de importância sanitária no Brasil. Rio de Janeiro: Editora Fiocruz; 1994.

25. Zar JH. Biostatistical analysis. $4^{\text {th }}$ Ed. Upper Saddle River: Prentice Hall; 1999.

26. Juliano SA, O'Meara GF, Morrill JR, Cutwa MM. Desiccation and thermal tolerance of eggs and the coexistence of competing mosquitoes. Oecologia 2002; 130:458-69.

27. Costanzo KS, Kesavaraju B, Juliano SA. Conditionspecific competition in container mosquitoes: the role of noncompeting life-history stages. Ecology 2005; 86:3289-95.

28. Chadee DD, Ward RA, Novak RJ. Natural habitats of Aedes aegypti in the Caribbean - a review. J Am Mosq Control Assoc 1998; 14:5-11.

Recebido em 18/Mar/2008

Versão final reapresentada em 08/Ago/2008

Aprovado em 29/Ago/2008 